\title{
EDUCAÇÃO FÍSICA E ÉTICA \\ CAMPO ONDE SE JOGA O DIÁLOGO E A MELHOR ARGUMENTAÇÃO
}

\author{
António Camilo Cunha* \\ Aguinaldo César Surdi** \\ Andrize Ramires Costa*** \\ Danieli Alves Pereira Marques ${ }^{\star \star * *}$
}

\begin{abstract}
RESUMO
Constata-se que existe uma tendência de olhar para a Educação Física num sentido de grande racionalidade técnica - vinda de fora - que conduz a uma atividade física instrumental, funcional, dicotômica, dualista, muito preocupada com a produtividade, eficácia, tendo como bússola orientadora a dimensão utilitarista. Ora, este fato parece emprestar um olhar moral e ético muito rígido, pouco flexível e de caráter quase intocável. No entanto, outros olhares "contrários" (diríamos complementares) vêm defender uma dimensão mais humanista sustentada pelas visões de intencionalidade fenomenológica, hermenêutica, interpretativa, onde é feito o elogio a um outro olhar axiológico.
\end{abstract}

Palavras chave: Educação Física. Moral. Ética.História. Argumentação. Diálogo.

\section{NOTA INTRODUTÓRIA}

Abordar a problemática dos valores (o axiológico) em termos gerais não é uma tarefa fácil, uma vez que eles têm valordiferente consoante os contextos culturais (esta é uma evidência). Ao abordá-los em termos educacionais, em particular na Educação Física/Movimento Humano (e remetendo-nos para a cultura ocidental), a tarefa continua a ser complexa. No entanto, vamos tentar fazer um exercício que nos permita visualizar melhor esse fenômeno e tentar ajudar a interpretá-lo à luz da práxis educativa. Uma coisa parece ser certa são os caminhos dos valores que parecem conduzir a humanidade no sentido do bem, do bom e do belo e são universais. Neste contexto, o ensaio que desenvolveremos está organizado em cinco momentos:O que são os valores e para que servem;A origem e os caminhos dos valores; Há coisas que é preciso fazer - Para uma Educação Física responsável;A ideia de argumento e a capacidade de estabelecer diálogos como fundamento da ética; Um exemplo de três bons argumentos.

\section{O QUE SÃO OS VALORES E PARA QUE SERVEM}

São vários os olhares sobre a práxis dos valores, que podemos encontrar nas mais diversas literaturas e nos vários cenários empíricos.

Os valores dizem respeito ao ser e às coisas do ser. Se quisermos, dizem respeito ao homem todo. Quando falamos do homem todo, podemos 
recuar ao homem helênico, em que o homem todo é o sensível (emoção), o inteligível (logos), o emanente (terreno) e o transcendente (Deus, livre arbítrio, imaginação).

Os valores funcionam como cimento (a moral) e ao mesmo tempo como mola de impulso para a ação (a ética). Os valores pretendem colocar em ordem! Temos aqui a ideia de ordem das coisas, ideia do homem colocar-se em ordem tão bem cantada, por exemplo, na ideia da cidade de ouro, do homem perfeito, das utopias (por exemplo, em Tomás Moro - a ilha da Utopia, olocus perfeito); do mundo inteligível (de Platão); ou mesmo em Aristóteles, que vai defender que a maior ordem é a virtude- $O$ Homem virtuoso é necessariamente feliz!

Os valores têm assim como função (grande função) guiar o homem na sua caminhada de vida, no sentido da vida e ao mesmo tempo preparar 0 homem para aquilo que há de vir - os fins últimos, o juízo final. Aqui temos a problemática religiosa e, se quisermos escatológica. Isto é, o problema dos fins últimos, a morte, a vida depois da morte, a existência de Deus. Este fato leva a angústias, expectativas, esperanças ou mesmo ao desassossego em que possamos viver - que encontramos, por exemplo, em Fernando Pessoa (2003).

Neste contexto, para aqueles que não acreditam em Deus - os valores são um caminho e um fim de dignidade (morrer digno), um juízo final com dignidade.

Para aqueles que acreditam em Deus, os valores são como uma mola de impulso para alcançar o Reino Santo (a Cidade de Deus, como refere Santo Agostinho). Aquela ideia de que os valores informam Deus sobre o progresso dos homens (Chardin, 2003). Ou aquela ideia de que se erramos é porque ainda "não" somos humanos".

Parecem existir vários níveis, tipos, ordens de valores. Nesta reflexão, vamos convocar os valores que estruturam o homem no caminho do bem, do bom e do belo. Os valores que estruturam o eu ontológico(ser em si, ser para si, e ser para o outro - ser experiência) e o ser antropológico e histórico.É neste envolvimento que encontramos valores como: o respeito, a justiça, a paz, a dignidade de vida, o amor, a solidariedade, a amizade, a honra, a humildade, a excelência, o trabalho, o esforço, a dedicação, a alteridade, o cuidado, valores que acabam por sustentar o homem virtuoso.

\section{A ORIGEM E OS CAMINHOS DOS VALORES}

Talvez possamos dizer com algum acerto que os valores têm uma origem diferenciada, o que não leva a um consenso fácil. Para uns, valores têm origem mítica, outros dizem que são resultado da constatação empírica (ser experiência), outros referem que são resultado de um exercício racional, outros apontam a origem metafísica ou ainda afirmam que os valores são de origem animal. Pensamos que eles são resultado de um pouco de cada olhar. Analisemos cada um deles: 


\section{A ORIGEM MÍTICA}

Se recuarmos um pouco ao tempo mítico (Bulfinch, 2006) -tempo do ato inaugural, do arquétipo, da origem imaculada - vamos constatar que o valor do valor (grande valor) é o respeito,e com ele há o aparecimento dos valores positivos - humildade, reconhecimento, bondade, amor, amizade. A amizade, por exemplo, nos diálogos platônicos é um valor extremo. Dizem que o céu e a terra estão unidos pela amizade. No sentido contrário- valores negativos -, temos a arrogância, a desobediência, a presunção, a vaidade. Alguns exemplos:

-Prometeu roubou o fogo aos Deuses e deu-o ao homem. Os Deuses castigaram-no, transformando-o em rocha. Roubar significa falta de respeito, sobranceria, falta de humildade. Mas, os Deuses (na sua infinita bondade) deixaram o fígado em que a águia vinha comer. Contudo, o fígado regenera-se. Do ponto de vista simbólico, o homem pode regenerar-se, e com ela a ideia de outra possibilidade - para atingir o respeito.

- Orfeu olhou para trás e ficou em estátua de sal. A arrogância de olhar para trás...

-ícaro voou alto demais e suas asas feitas de cera lentamente foram derretendo, o que provocou sua morte no oceano.

A presunção e a vaidade de voar alto de mais...

- Adão e Eva (o nosso mito), que depois do bom conselho (sobre o bem) seguiram o mau conselho (comeram a maçã), conhecendo assim o mal. $\mathrm{Na}$ tradição católica/cristã a partir de então o homem vive numa luta interminável entre o bem e o mal.

\section{A CONSTATAÇÃO EMPÍRICA}

Depois do mito emerge a empiria. Estamos a situar-nos no início da cultura ocidental ${ }^{2}$. Constata-se que o período pré-Grécia e o início do período Grego (portanto há 2400 anos) são um tempo em que a guerra, o sofrimento, e a dor são uma realidade radical. A este propósito, diz-nos Nietzsche (2003, 2004):

Assim, os gregos, os mais civilizados dos homens da antiguidade, sustentam um traço de crueldade, um perigo tigrino de destruição - por exemplo:

"Alexandre, quando manda furar os pés de Bátis (corajoso defensor de Gaza) e ata o corpo ainda com vida, ao seu carro, para escárnio dos soldados. Ou mesmo Aquiles, que, de modo semelhante, maltrata o cadáver de Heitor" (Nietzsche, 2003, p.31).

Por que razão tinham os escultores Gregos de gravar, e tornar a gravar, em incontáveis repetições as guerras e as lutas? 
Por que razão jubilava o inteiro mundo Grego com os inúmeros combates da llíada? Sucessões quase ininterruptas de episódios sangrentos?

Era o tempo em que a paz era uma miragem, nunca alcançada, e a dor, o grande legado dos homens.

Todo este cenário é uma herança do período pré-helênico, diz-nos Nietzsche. Neste tempo, existia o horror, os filhos da noite, o conflito, o engano e a morte. Nesta atmosfera abafada, a luta representava a felicidade, a salvação, a vitória - o ápice do Júbilo vital.

Assim, a cultura Grega vai, num primeiro momento, assimilar este quadro pré-grego. Aceita o instinto terrível e considera-o legítimo. Foi este cenário que inspirou os escultores e os poetas, tendo como pano de fundo as guerras e as lutas (tragédia grega).

\section{O EXERCÍCIO RACIONAL}

Perante este cenário (guerra), surge um homem, Sócrates, que faz elevar um novo quadro moral e ético. Sócrates vem fazer o elogio ao valor da vida, o elogio à existência, à racionalidade, ao areté (excelência), à paideia... e com ela a morte da tragédia. Sócrates será o destruidor da tragédia. É a partir de Sócrates (e, sobretudo, a partir de sua morte, na voz de Platão - Diálogos Platônicos) que surge o elogio à vida e à existência, que irão constituir-se mais tarde como sementes do cristianismo e do judaísmo.

A partir daqui estavam encontrados os dois caminhos que iriam estruturar e orientar a conduta e a caminhada do homem ocidental - A moral e a ética.

Gostaríamos de deter-nos um pouco neste ponto colocando as questões:

\section{O que é a moral e o que é a ética?}

A Moral tem origem no Latim (mos-moris), significa costume, caráter, modo de ser. Por sua vez, a Ética apresenta-se como uma forma nominal de origem Grega (já presente na antiga poesia Grega) derivada do substantivo neutro Êthos - que significa morada, toca, lugar onde vivemos, estância. A partir de Hesíodo, o termo assume uma evolução semântica, passando a corresponder à significação, maneira de ser habitual, disposição de espírito, caráter, interioridade de que brotam os atos (BRITO, 2007).

Constatamos que há autores que utilizam a moral e a ética com o mesmo significado de Cabral (2000), e outros que recorrem aos dois termos para significar conceitos diferentes (LADRIĖRE, 1997). Neste contexto, Ricoeur (1990; 2000), concordando com a existência dos dois termos, elabora uma pequena taxonomia sobre a moral e a ética. Segundo ele, a moral é o anterior. É o enraizamento das normas da vida (o fixo), é o desejo, a moral pensada (ARANGUREN, 1994), a institucionalização de códigos, a norma jurídica. É o fundamental - são os mínimos. 
A ética,por seu lado, diz respeito ao posterior. Corresponde ao enraizamento das normas nas situações concretas. É o aplicado, a moral vivida (ARANGUREN, 1994). Quando isso acontece (a moral vivida), estamos no campo da ética - são os máximos.

A ética é assim uma reflexão crítica, filosófica sobre a moral na procura daquilo que a caracteriza e a justifica. Neste contexto, Cortina \&Martinéz (1994), referem também que a ética tem três funções: clarificar o que é o moral e quais as suas características específicas; fundamentar a moralidade; aplicar aos diversos âmbitos da vida humana o que se descobriu nos primeiros pontos. Ou, como afirma Etxeberria (2002), a função da ética é precisar os bens supremos, imperativos, regras, que se constituem como referencial moral último das nossas ações - incitar à vivência da vida moral como expressão da humanidade do ser humano (PIEPER, 1990).

Aqui, poderemos fazer emergir uma primeira ideia. A moral corresponde a uma atmosfera teórica, normativa; a ética corresponde à prática pela procura da vida boa -vida boa individual, social,formativa e educativa que tem na dimensão axiológica o bom porto.

Chegamos a um ponto que talvez mereça uma pequena clarificação para percebermos melhor o slogan atual - vivemos numa crise de valores (e perceber melhor a formação e educação). Assim, num primeiro momento, a moral (o dizer moral) correspondia à ética (o fazer ético). Esse(s) primeiro(s) momento(s) podemos encontra-lo(s) no período helênico, no período romano (com as leis jurídicas/direito romano) e na apropriação religiosa (judaico-cristã), levando ao estabelecimento de uma máxima: a de que ser moral é ser ético, ou seja, que a moral e a ética têm a mesma força.

Já num segundo momento - estamos agora situados na modernidade, iluminismo - Séc. XVII. É um tempo em que há uma profunda crença na razão. Convições como: a razão leva à libertação, a razão é larga, há uma necessidade de acordar do sono da razão... são agora elogiadas.

Um terceiro momento podemos dizer que é aquele que vai dizer e estruturar o Séc. XX (a emergência da pós-modernidade) e com ela fenômenos como: a elevação da técnica, a secularização, o fim das grandes narrativas, o niilismo, o hedonismo... Ora, parece que todos estes acontecimentos fizeram com que a ética se tornasse rebelde, se tornasse mais forte.

A moral continua a existir (valor fundador - não devemos renegar a raiz, o início), mas a ética parece que deixou de ser obediente. Isto é, a ética tem-se distendido, distanciado, afastado, contestando a própria moral. Neste sentido, talvez possamos dizer com algum acerto que não temos crise de valores, temos eventualmente um novo pensamento e agir ético ${ }^{3}$.

É neste contexto que descem novas luzes (BAPTISTA, 1998) sobre esta nova relação entre a moral e a ética.

- A moral parece condicionar a liberdade, ao passo que a ética a interpela. 
- Onde uma impõe, a outra propõe. É precisamente quando a moral é interpelada e o mundo proposto que emerge a consciência ética.

- Se a moral traça fronteiras estratégicas, a ética ajuda a subvertê-las abrindo espaços à plenitude de sentidos que serve a vida humana.

- Onde a moral canaliza, liga e unifica, a ética desliga e desnuda visando o que fica fora dos hábitos e dos modelos padronizados.

- A ética traz consigo uma liberdade (responsável), a plenitude de sentidos, a força da coragem.

- A ética estimula novas interrogações. Interrogações incômodas, causadoras de desassossego, mas interrogações que abrem espaço ao desejo, à palavra, ao tempo e à criatividade.

Esta nova ética serve por assim dizer para dar razão, isto é, para fundamentar.

\section{ORIGEM ANIMAL}

Os valores são de origem animal. Valores como a prudência, a amizade, o caráter, o cuidado, o perdão (o verme que perdoa ao arado)... são de origem animal como refere SINGER (1991). O homem, quando se sentir só, quando estiver a atravessar as areias do deserto, as dores do deserto, não fique lá, não fique só, procure a companhia dos animais. Não devemos esquecer a nossa parentela animal e sua amável e terna companhia.

\section{HÁ COISAS QUE É PRECISO FAZER - PARA UMA EDUCAÇÃO FíSICA RESPONSÁVEL}

Ricoeur (2000) afirma que há um problema moral, porque há coisas que é preciso fazer ou que vale mais a pena fazer que outras. Há coisas que têm que ser feitas ou que é bom que sejam feitas para que possam ter um sentido moral de cariz ético.

A Educação Física ${ }^{4}$ parece viver ainda numa lógica de regra, regulamento, podendo estar próxima de uma regra moral que ao mesmo tempo poderá ser um problema moral. Este fato é resultado da constatação que a Educação Física na sua essência é larga e democrática e não apenas um instrumento ideológico - político (como a história da Educação Física em alguns momentos mostra), ou um instrumento curricular de um ou outro sentido dominante.

Se olhássemos um pouco para o futuro, seria importante reconhecer uma moral universal, ou melhor, uma moral que congregue todos os sentidos (concepções) de Educação Física. Isso valerá a pena fazer, pois a realidade global e local assim o determina. Fazer, ou fazer melhor, está assim em cima da mesa para uma práxis de uma Educação Física responsável.

Há a necessidade de uma ética posterior - pegando nos contributos de Ricoeur (2000) - para a Educação Física, ou seja, de uma moral ética, 
contrariando a moral dominante que parece elevar a ideia de uma norma educativa, formativa, curricular de determinada maneira. Esta maneira é quase única (desportivista, técnica), pondo em causa, por exemplo, a dimensão subjetividade e intersubjetividade, coisas primeiras, pertencentes à dimensão humana.

Assim, uma ética anterior fundamentada dando luz a uma ética posteriorconcretizada aceitará a ideia de reflexão sobre a vida escolar, formativa e, sobretudo, prática. Trata-se de elaborar o que podemos chamar de ética aplicada de sentido total e radical - o homem como ser total e radical. A ética impõe-se pela sua própria virtude, sem ter que ficar amarrada a fundamentos exteriores (currículo, programa) - ela pertence à constituição humana e é a ela que deve servir.

Neste contexto, talvez possamos diferenciar a norma moral (no sentido ético) da norma curricular e formativa dominante, para perceber onde é que estamos e que há coisas que é preciso fazer:

- A norma moral vale pela consciência moral, sendo o seu valor independente da sua integração no sistema educativo, formativo, curricular; a norma curricular e formativa, por seu turno, tem seu valor depois do aceite pelo poder educativo e legislativo - lei.

- A norma moral tem uma prescrição (dever fazer) interna, é a própria consciência moral que exerce coação; a norma curricular e formativa, por seu lado, tem mecanismos exteriores de coação caracterizadas no poder "repressivo" do currículo - quando fechado e fixo, entenda-se.

- A norma moral que é também da ordem espiritual diz respeito aos indivíduos (mundos pessoais - pessoa enquanto ser moral); a norma curricular e formativa (de dimensão mais material) diz respeito à instituição aos programas. Estas duas normas muitas vezes não coincidem.

\section{A IDEIA DE ARGUMENTO E A CAPACIDADE DE ESTABELECER DIÁLOGOS COMO FUNDAMENTO DA (MORAL) ÉTICA NA EDUCAÇÃO FísICA}

Perante a exposição anterior, temos um problema teórico e, sobretudo, prático. Como fazer com que estas duas normas coincidam? Como fazer com que a moral de cariz ético esteja na Educação Física em equilíbrio?

Uma possível resposta poderá ser dada pela ideia de diálogo e argumentação: a capacidade de estabelecer diálogos pela capacidade de estar junto. É o diálogo que agora vai comandar a negociação moral e ética. Esta ideia de diálogo pode ser sustentada por uma ética do discursoque encontramos, por exemplo, em Habermas(1988).

A Formação, a Educação (Física) e a Escola são agora construídas em sociedade e em grupo - retorno à polis. A ética é do tempo e dos espaços do 
homem. A ética tem uma história (não nega a história) sustentada pela linguagem, participação, comunicação, discurso, argumentação, diferença, multiculturalidade, identidade, intersubjetividade.

O agir comunicativoforte e rigoroso (argumentação) cria uma consciência moral e ética. Há agora uma ética que "não é" da ordem do universal por ser transcendental"não" é da ordem de um a priori ou de uma racionalidade atemporal, mas uma ética em que todos os indivíduos (professores, alunos, comunidade...) chegam a um acordo. $O$ argumento, 0 melhor argumento(s) é aquele que vai ser o adotado e sustentado em regras que são agora legitimadas, validadas e partilhadas pelo grupo na construção de um projeto ético rigoroso. Não são as diferenças (autoritárias, individualistas, curriculares...) que têm força, mas a qualidade dos argumentos.

\section{EM JEITO E CONCLUSÃO: TRÊS BONS ARGUMENTOS}

$\mathrm{Na}$ linha de pensamento que temos discorrido, talvez possamos dizer que a Educação Física se situe num quadro ao mesmo tempo moral e ético (a tradição); e um quadro moral onde parece existir uma distensão, distanciamento da ética, uma nova moral ética. Este fato pode ser ilustrado pelo conceito de corpo (eu) substancial e corpo (eu) relacional.Senão vejamos:

O corpo (eu) substancial - olhar para a Educação Física como uma construção sociológica, política, cultural e racional, tomando como referência regras, padrões, expectativas, esperanças, deveres, relações pretensamente igualitárias. A Educação Física é assim do campo da atividade física, da saúde, da técnica, da prática, da eficácia, da melhoria, do externo. É do campo do uniforme, da certeza, da rivalidade controlada, da competição muitas vezes manipulada. Ora, o que parece sustentar e trespassar este olhar é a ideia de ordem (máxima axiológica - a ordem como valor moral e ético). A ordem das coisas que necessita de uniformidade, integração, harmonia. Vista desta perspectiva, a educação, a escola e o ensino são "coisas" para por ordem sentido moral juntamente com um fazer ético:organizar racionalmente o mundo da liberdade. Temos aqui o campo do movimento humano um homo QUE movens (que diz o homem substancial), em que a ideia (práxis) de conduta, diálogo, agir é sempre feita em relação a uma função que controla e manipula. A trilogia sujeito, contexto e significaçãoparece ficar fechada, acorrentada num mundo que dói, mundo sem vazio, mundo cheio de ordem racional. Este é um argumento (introduzimos esta ideia de argumento). As normas culturais, políticas e ideológicas, neste sentido, parecem revestir-se como um "bom" argumento.

O corpo (eu) relacional - olhar para a Educação Física como tempo e espaço do eu - aí, do eu-mundo -, outro no sentido do diálogo; ou do estar junto. A Educação Física emerge assim como algo que vem de trás, que vem de longe, e com ela a ideia de estrangeiro. Este estrangeiro que é novo, que tem em si o que é seu, mas que também é do outro. Por isso, o diálogo 
aparece como forma de ligar, (re)ligar continuamente pela palavra (que é mais forte que a linguagem), pela surpresa, pela revelação, nunca antes vista, sentida ou partilhada. Assim, a intervenção pedagógica é feita em função de uma ordem que vem de longe e que traz o sentido de liberdade e de livre escolha. Temos aqui o campo do movimento humano um homo SE movens (que diz o homem relacional), em que a ideia (práxis) de conduta, diálogo, agir é sempre feita em relação a um "se-movimentar", proposto por Kunz (2001), a uma autonomia, crítica - crítica, diálogo, coisa própria, amor, imaginação. Tudo isso pela vida toda como ser de ação materializada e espiritualizada em relações significativas. A trilogiasujeito, contexto e significação fica aberta, receptiva à constante mudança. É a metáfora da dança - mundo que dança, sujeito que dança. É na dança que se compreende o ritmo - igual, diferente, com riso e sorriso do ser, de ser e do mundo. Este é um outro argumento. A intencionalidade, a ação entra no vazio (caixa com funda sem fundo) e trás 0 novo e a abertura à existência (ecologia interna e externa), à experiência. Estes fatos parecem revestir-se também como um "bom" argumento.

Perante estes dois "bons" argumentos, tomamos a liberdade de acrescentar um terceiro argumento - diálogo na integração. Pensamos que, num mundo pré-estabelecido, pré-dado, pré-existente (moral), é na capacidade de ser mais, somar e transformar em liberdade (que se encontra no vazio) que entramos no campo da ética. Afinal, é o momento de liberdade que permite a dança - dança que confirma e perpetua o si-mesmo, o outro-mesmo e o nós mesmo. E perpetuar isto é perpetuar a humanidade.

Talvez possamos dizer que o corpo relacional é anterior ao pensar do corpo substancial; que o corpo substancial é um subsistema do corpo relacional, que épré-reflexivo.Quando se trata de ações constituídas na relação sujeito-mundo, de experiência corporal vivida, temos o "corpo-relacional", ação viva. Por isso, Merleau-Ponty (1999) aponta que, "o movimento não é o pensamento de um movimento, e o espaço corporal não é um espaço pensado ou representado" (p. 192). Sendo assim, não devemos nunca "dizer que nosso corpo está no espaço e nem tampouco que ele está no tempo" (p.193), pois ele é o espaço e o tempo. O pensamento sobre o corpo jamais substituirá o lugar da vivência corporal, assim, para Heller (2003) haverá sempre diferença em afirmar que o corpo se move para expressar-se ou "[...] ele se expressa movendo-se" (p. 63). O pensamento (corpo substancial) perece não perceber, ou não permitir esse corpo iniciático e atemporal; aquele corpo que consegue chegar ao fim da caixa que não tem fim; aquele corpo que consegue resgatar continuadamente o vazio. É nesse vazio que se encontra a ideia de ser e sentido, de diálogo, do ser aí (Dasein), do estar aí. Aquele vazio que permite mostrar o movimento como forma de existir e que mostra também o existir. Este será apenas um outro argumento no campo da Educação Física e da ética. 


\section{REFERÊNCIAS}

ARANGUREN, J.Ética. Madrid: Alianza Editorial, 1994.

AZEVEDO, E. S. DE; SHIGUNOV, V. Reflexões sobre as abordagens pedagógicas em Educação Física. In: SHIGUNOV, V; NETO, A. S. (Orgs.). A formaçãoprofissional e a prática pedagógica: ênfase nos professores de Educação Física. Londrina: O Autor, 2001. p.77-94.

BAPTISTA, I. Ética e educação - estatuto ético da relação educativa. Porto: Universidade Portucalense, 1998.

BRITO, J.Ética e Moral. In: (Coord). Ética das profissões. Braga: Faculdade de Filosofia - Universidade Católica Portuguesa, 2007.p.16-31.

BULFINCH,T. O livro de ouro da mitologia: história de deuses e heróis. Rio de Janeiro:Ediouro, 2006.

CABRAL, R.Temas de ética. Braga: Faculdade de Filosofia - Universidade Católica Portuguesa, 2000.

CHARDIN, P. The human phenomenon. Brighton: Sussex Academic, 2003.

CORTINA, A.; MARTINÉZ, E.Ética. Madrid: EdicionesAkal, 1994.

CAMILO CUNHA, A."Mais" protestantes e "menos" católicos. In: Pereira, B.; Carvalho, G. (Org.). Actividade física, saúde e lazer. A infância e os estilos de vida saudável. Porto: Lidel Editores, 2006. p.155-188.

ETXEBERRIA, X. Temas básicos de ética. In: Ética de lasprofissiones. Bilbao: Desclée De Brouwer, 2002 pp.62-73.

HABERMAS, J. (1988).Teoría de laacción comunicativa. Racionalidade laacción y racionalización social. Madrid: Taurus, 1988. 2 v. 
HELLER, A. A. Ritmo, motricidade, expressão: o tempo vivido na música. Dissertação (Mestrado em Educação). Centro de Ciências da Educação, Universidade Federal de Santa Catarina, Florianópolis, 2003.

KUNZ, E. Educação Física: ensino \& mudanças. ljuí: Unijuí, 2001.

LADRIÉRE J.Le concept de dimensionéthique .In: . L'éthiquedans I 'únivers de la rationalité.Saint Laurent/Nanur: Fides/Artel,1997. p. 21-42.

MERLEAU-PONTY, M. Fenomenologia da Percepção. Tradução de Carlos A. R. Moura. 2 ed. São Paulo: Martins Fontes, 1999.

NIETZSCHE F. A competição em Nietzsche. Lisboa:Vaga, 2003. NIETZSCHE F.A origem da tragédia. Porto:Editora Campo das Letras, 2004.

PESSOA, F. Livro do Desassossego. Lisboa: Edições Richard Zenith, Assírio \& Alvim, 2003.

PIEPER, A. Ética y moral. Una introducción a la filosofia prática. Barcelona: Editorial Crítica, 1990.

RICOEUR, P.De lamorale à l'èthique et auxéthiques.UnSiècle de Philosophie. Paris:Centre Pompidou, 2000.

RICOEUR, P. Soi-mêmecommeunautre. Paris: Seuil, 1990.

SINGER, P. Liberazioneanimale.New York: A. MondedoriEditores, 1991.

\section{PHYSICAL EDUCATION AND ETHICS PLAYING FIELD WHERE THE BEST DIALOGUE AND ARGUMENTATION}

\section{ABSTRACT}

It appears that there is a tendency to regard the Physical Education with a sense of high technical rationality - from outside - that leads to an instrumental, functional, dichotomous, dualistic physical activity, very concerned with productivity and effectiveness, having as orientation an utilitarian dimension. Now, this fact seems to borrow a very rigid moral and ethical look, with little flexibility and almost untouchable character. However, other "contrary" (we say additional) looks defend a more humanistic dimension supported by visions of phenomenological, hermeneutic, interpretative intentionality, where a compliment to another axiological look is made.

Key-words:PhysicalEducation. Moral.Ethic.History.Argumentation. Dialogue. 
EDUCACIÓN FISICA Y ÉTICA

CAMPO DONDE SE JUEGA EL DIÁLOGO Y LA MEJOR ARGUMENTACIÓN

\section{RESUMEN}

Se constata que hay una tendencia a considerar Educación Física en el sentido de gran racionalidad técnica - desde el exterior - y que lleva a una actividad física instrumental, funcional, dicotómica, dualista, muy preocupada por la productividad, la eficacia, teniendo como brújula orientadora la dimensión utilitarista. Sin embargo, este hecho parece echar una mirada ética y moral muy rígida, poco flexible y de carácter casi intocable. Con todo, otras miradas "contrarias" (diríamos, complementarias) abogan por una dimensión más humana sostenida por las visiones de la intencionalidad hermenéutica fenomenológica, interpretativa, donde se hace el elogio a una otra mirada axiológica.

Palabras clave:Educación Física. Moral. Ética. Historia. Argumentación. Diálogo.

Endereço para correspondencia: 


\footnotetext{
${ }^{1}$ Sobre esta problemática dos valores e do religioso, gostaríamos de deixar três ideias significativas: a) Um dia, perguntaram ao Papa João Paulo II como explicava racionalmente a existência de Deus. A resposta foi tão singela quanto profunda: Eu não explico, por isso acredito! b) Pascal (homem da Ciência) dizia que existiam dois tipos de homens razoáveis: os que acreditam em Deus e estão com Ele; os que não acreditam, mas que $\mathrm{O}$ procuram. c) Se quisermos, no sentido mais terreno (mundano), foram os epicuristas que deram a resposta mais simples: "vocês não sabem como nasceram, também não saberão o que é morrer - por isso estejam, fiquem descansados".

${ }^{2}$ Quando falamos na Cultura Ocidental,estamos a falar de regiões/países como: Canadá, E.U.A, América do Sul, Europa e eventualmente Austrália. A máxima moral e ética que trespassa todos eles é a ideia (helênica): homem (vida, natureza) como dignidade absoluta.
}

${ }^{3} \mathrm{Na}$ cultura helênica, na lei romana (lei positiva), no cristianismo...esta lei moral tinha uma correspondência ética - um agir ético. A não obediência a esta lei moral levaria ao castigo da lei, do remorso, da culpa. A moral e a ética juntas tinham uma métrica, geometria, avaliação. Quantas vezes pecaste? Quantas vezes mentiste? Quantas vezes foste desobediente? A uma métrica do pecado havia uma métrica do perdão. Com a modernidade e pós-modernidade, a lei moral continua a existir, mas a ética conseguiu distender-se...

${ }^{4}$ Depois deuma análise às varias concepções de Educação Física, Azevedo \&Shigunov(2001), talvez possamos fazer uma pequena taxonomia a quem vamos dar o nome: as três Educações Físicas características e possibilidades:

$1^{a}$ Educação Física (do ser)- O diálogo comigo mesmo é caminho para a dimensão fenomenológica. Dizer de mim mesmo, ser através de mim...e deixar ser para mim. $\mathrm{O}$ eu da experiência, da consciência que dá sentido à vida, voltando para si mesmo. Ser-no-mundo; mundo vida. A educação Física como retorno às coisas próprias, ao primeiro conhecimento, à consciência, à experiência, ao corpo. Todo corporal, todos os sentidos, corpo aberto sem especializações, o corpo com o outro. Diálogo com o outro que sou eu, e o eu que é o outro;eu- tu e o eu- outro. Nesta concepção,é a Educação Física que mostra o corpo e o seu vazio (ideia de vazio). Um vazio cheio de experiência, consciência, intimidade, emoção, intencionalidade, luz, movimento quente, imaginação, sensibilidade, arquétipo, alteridade, resguardo, auxílio, sentido, redução, parêntesis, horizonte, excelência. Mostra um falarem que as palavras são mais fortes que a linguagem; um refletir em que existe ação e depois pensamento; um transformar, pela invenção humana, sempre...;

$2^{\text {a }}$ Educação Física (da escola) - Diálogo com o ensino de corpos. Ensino de regras, normas, comportamentos para preparar o futuro: corpo objeto, corpo destino, corpo movimento. Civilizar, socializar, politizar o corpo e o movimento como caminhos a seguir, pois o educar é resultado de um sentir do futuro - perpetuação e melhoria do futuro, e nesse sentido idealizado por concepções políticas, sociais, culturais e históricas.O eu-isso, o outro-isso, o nós-issorevestem-se de sucesso, de vivência de 
causas, em que a racionalidade, a cultura, a ciência são como baluartes de ação. Mostra um falar pela linguagem que é mais forte que as palavras; um refletirem que existe pensamento e depois ação; um transformar pelo controle e manipulação humana, sempre.No entanto, e tomando como referência a temática deste escrito, consideramos que uma moral ética na escola deverá convocar três dimensões estruturantes: a) ética social - no espaço escolar (que é público,), crianças e jovens devem viver e conviver com diversas dimensões motoras (e tudo o que isso envolve). Neste sentido, a Educação Física deve encontrar referências de movimento humano comuns e partilhadas. Sendo assim, far-se-ão as desejáveis e necessárias autonomia e liberdade motora; b) ética pessoal - há que encontrar uma resolução curricular e formativa entre as "tensões" provocadas pelos "eus" individuais, tendo como referência última o agir/ação e os "issos" curriculares. Ética reflexiva - esta tem consequências práticas. Ao discutirse a dimensão curricular, espera-se que seja uma reflexão individual e ao mesmo tempo comum na convivência motora. A ética faz valer uma exigência global (argumentação), mas toma o seu conteúdo na concretude das circunstâncias particulares;

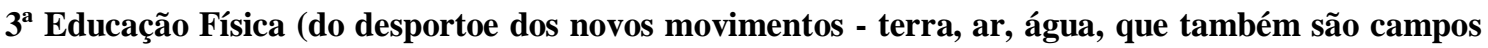
da $\mathbf{1}^{\mathbf{0}}$ e $\mathbf{2}^{\mathbf{0}}$ Educação Física) - Desporto faz uma vida. É uma metáfora da vida, para o bem ou para o mal. Neste sentido, é consensual a necessidade de um caminho ético. Quanto maior o nível de consciência, maior o nível ético - desporto como lócus de consciência;desporto que convoca a $\mathbf{1}^{\mathbf{a}}$ Educação Física Desporto aberto no qual o tempo, o espaço, os materiais são da ordem do provável improvável. Desporto onde o errar é permitido, onde a capacidade de surpreender-se a si mesmo é mais forte que surpreender os outros (poder), onde o riso e sorriso imperam, onde as perguntas são permitidas, onde o corpo "nu" com alma se pode expressar, onde o imprevisível que traz sempre o espanto acontece. Desporto que convoca a $2^{\mathbf{a}}$ Educação Física - Desporto fechado, vestido com rendimento, que quer surpreender os outros. Desporto do não errar, do certo, das respostas, da racionalidade da ação onde a imaginação e a revolta parecem ser reduzidas ao já pensado. 